\title{
Review
}

\section{Cyclic nucleotide phosphodiesterases in pancreatic islets}

\author{
N. J. Pyne, B. L. Furman \\ Department of Physiology and Pharmacology, Strathclyde Institute for Biomedical Sciences, University of Strathclyde, \\ Glasgow, Scotland
}

\begin{abstract}
Cyclic nucleotide phosphodiesterases (PDEs) comprise a family of enzymes (PDE1-PDE11) which hydrolyse cyclic AMP and cyclic GMP to their biologically inactive $5^{\prime}$ derivatives. Cyclic AMP is an important physiological amplifier of glucose-induced insulin secretion. As PDEs are the only known mechanism for inactivating cyclic nucleotides, it is important to characterise the PDEs present in the pancreatic islet beta cells. Several studies have shown pancreatic islets or beta cells to contain PDE1C, PDE3B and PDE4, with some evidence for PDE10A. Most evidence suggests that PDE3B is the most important in relation to the regulation of insulin release, although PDE1C could have a role. PDE3-selective inhibitors augment glucose-induced insulin secretion. In contrast, activation of beta-cell PDE3B could mediate the inhibitory effect of IGF-1 and leptin on insulin secretion. In vivo, although PDE3 inhibitors augment glu-
\end{abstract}

cose-induced insulin secretion, concomitant inhibition of PDE3B in liver and adipose tissue induce insulin resistance and PDE3 inhibitors do not induce hypoglycaemia. The development of PDE3 inhibitors as anti-diabetic agents would require differentiation between PDE3B in the beta cell and that in hepatocytes and adipocytes. Through their effects in regulating beta-cell cyclic nucleotide concentrations, PDEs could modulate beta-cell growth, differentiation and survival; some work has shown that selective inhibition of PDE4 prevents diabetes in NOD mice and that selective PDE3 inhibition blocks cytokine-induced nitric oxide production in islet cells. Further work is required to understand the mechanism of regulation and role of the various PDEs in islet-cell function and to validate them as targets for drugs to treat and prevent diabetes. [Diabetologia (2003) 46:1179-1189]

Keywords Islet beta cell, phosphodiesterase, cyclic AMP, cyclic GMP, insulin secretion.
Received: 28 February 2003 / Revised: 8 May 2003

Published online: 7 August 2003

CC Springer-Verlag 2003

Corresponding author: B. L. Furman, Department of Physiology and Pharmacology, Strathclyde Institute for Biomedical Sciences, University of Strathclyde, Taylor Street, Glasgow, G4 0NR Scotland

E-mail: b.l.furman@strath.ac.uk

Tel.: +44-141-5484707

Abbreviations: PDE, phosphodiesterase; GIP, glucose-dependent insulinotropic peptide; GLP-1, glucagon like peptide 1; PDX-1, pancreatic duodenal homeobox-1; IBMX, isobutylmethylxanthine.

\section{Introduction}

Cyclic nucleotide phosphodiesterases comprise a family of enzymes the function of which is the hydrolysis of cyclic AMP and cyclic GMP to their biologically inactive $5^{\prime}$ derivatives. Currently there are 11 known gene families of CN-PDEs consisting of more than 50 enzymes with differences in their substrate selectivities (cyclic AMP vs cyclic GMP), kinetics, allosteric regulation, tissue distribution and susceptibility to pharmacological inhibition (see reviews $[1,2,3])$. The main properties of some of these enzymes are shown in Table $1[3,4,5,6,7,8$, $9,10,11,12,13,14,15,16,17]$. In view of the clear 
Table 1.

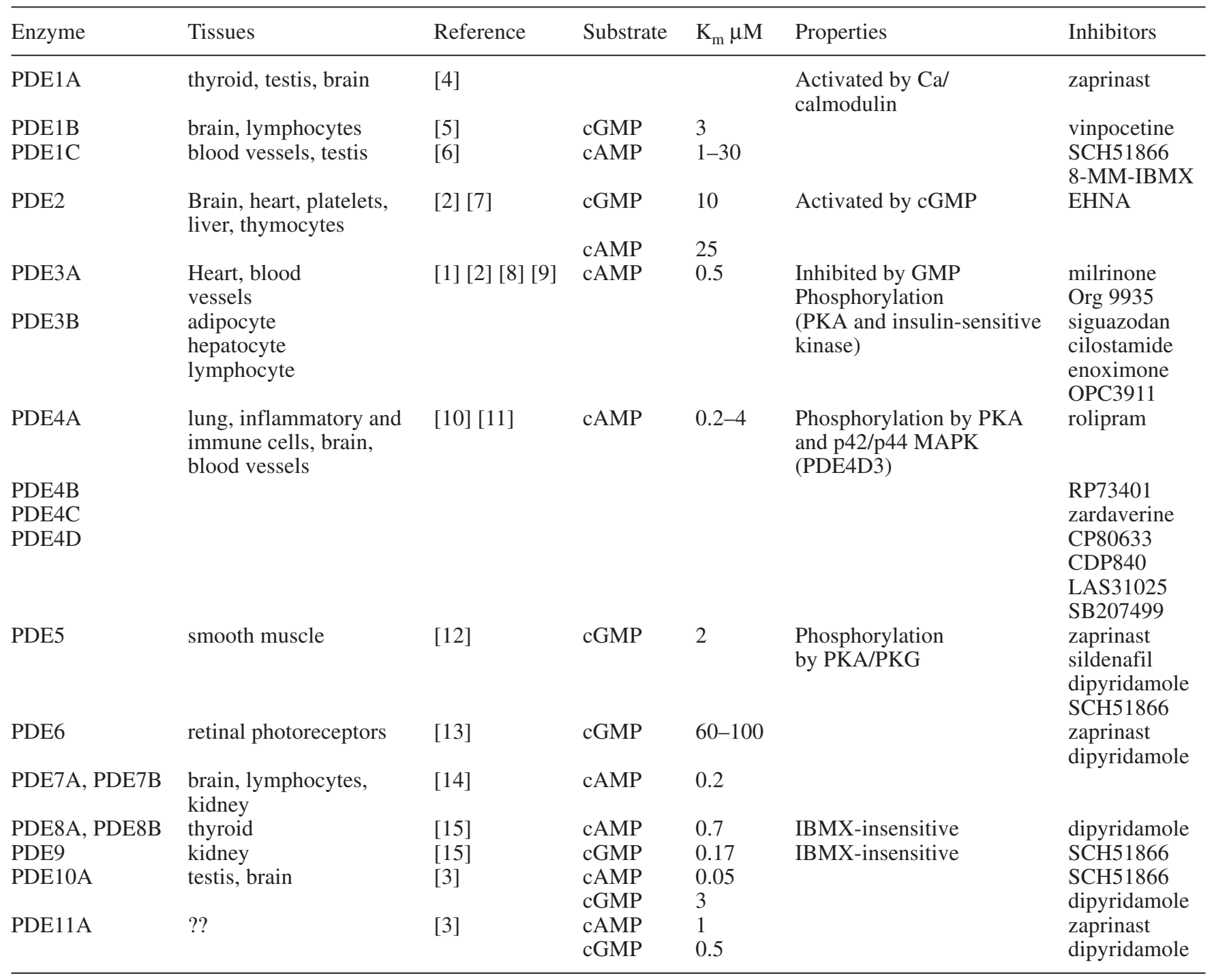

importance of cyclic nucleotides, especially cyclic AMP, in the pancreatic islet beta cell and the fact that phosphodiesterase-activity is the only known system for destroying these cyclic nucleotides, it is important to understand the nature and the roles of the phosphodiesterase enzymes expressed in islet beta cells. The aim of this short review is to examine two main questions: (i) what phosphodiesterase (PDE) isoenzymes are expressed in the pancreatic islet beta cell? (ii) which PDE isoenzymes are functionally important in regulating cellular cyclic AMP concentrations in relation to insulin secretion?

\section{Roles of cyclic nucleotides in the pancreatic islet beta cell}

cAMP

Insulin secretion

Although glucose-induced insulin secretion does not seem to require increases in islet beta-cell cyclic AMP or the PKA-system [18, 19], intracellular concentrations of cyclic AMP in beta cells are increased by glucose $[20,21]$. Moreover, this cyclic nucleotide is generally accepted as an important amplifier of glucoseinduced insulin release [22], particularly when its cellular concentrations are increased by various gut hormones implicated as incretins but also by glucose itself [23]. Cyclic AMP augments glucose-induced insulin secretion through a number of mechanisms including increased opening of voltage-sensitive $\mathrm{Ca}^{2+}$ 
channels [24], calcium-induced $\mathrm{Ca}^{2+}$-release [25], activation of ryanodine receptors in the $\operatorname{ER}[26,27]$, stimulation of beta-cell lipolysis [28] and direct effects on exocytosis [23]. Most actions of cyclic AMP in the beta cell seem to be mediated through proteinkinase A (PKA)-catalysed phosphorylation events but direct effects of the cyclic nucleotide on exocytosis are partly PKA-independent [29]. PKA-independent effects on exocytosis can be mediated by the cyclic AMP-binding protein cAMP-GEFII, interacting with Rim2, a target of the small G-protein Rab3 [30]. Cyclic AMP mediates the insulinotropic action of the incretin factors glucose-dependent insulinotropic peptide (GIP) and glucagon like peptide 1 (GLP-1) [31]. GLP-1 is released during meals and markedly augments the direct effect of glucose on insulin secretion via cyclic AMP-dependent mechanisms.

\section{Other roles in the beta cell}

In addition to its role in amplifying glucose-induced insulin secretion, cyclic AMP can mediate or modulate other effects of glucose and insulinotropic hormones in the beta cell. Glucose-mediated increases in insulin synthesis involve the phosphorylation of the transcription factor pancreatic duodenal homeobox-1 (PDX-1) and its translocation to the nucleus [32]. Whereas the effects of glucose on PDX-1 are not mediated by cyclic AMP, there is strong evidence for the importance of cyclic AMP in GLP-1-dependent stimulation of PDX-1 in the beta cell, as well as its translocation to the nucleus and its activation of the insulin gene promoter [33]. However, the role of cyclic AMP in regulating insulin synthesis is not clear because the adenylyl cyclase activator forskolin, or the cyclic AMP analogue 8-bromo-cyclic AMP suppressed insulin transcription in INS-1 cells in a PKA-independent manner [34]. Cyclic AMP could mediate effects of glucose in stimulating the expression of immediate early response genes such as $c$-myc [35] and $c$-fos [36]. In this context, cyclic AMP can either activate or inhibit the p42/p44 mitogen-activated protein kinase pathway depending on the cell type and conditions [37]. Glucose itself activates the $\mathrm{p} 42 / \mathrm{p} 44$ MAPK pathway $[38,39]$ and this effect is amplified, although not mediated by, cyclic AMP. Indeed, the activation of this pathway by GIP is cyclic AMP and PKA-dependent [40]. Regulation of gene expression by cyclic AMP could have relevance to effects on beta-cell growth, differentiation and apoptosis. For example, increased cyclic AMP concentrations protected rat islets against interleukin-1 beta mediated induction of nitric oxide synthase and nitric oxide production [41]. Excessive nitric oxide production seems to mediate subsequent apoptosis of beta cells. On the other hand, beta-cell lines were made more susceptible to apoptosis after exposure to dibutyryl cyclic AMP [42] or the cyclic AMP-increasing agent forskolin [43].

\section{Cyclic GMP}

Although increases in cyclic GMP have been linked with decreases in insulin secretion $[44,45]$, the role of this nucleotide in the islet beta cell remains unclear $[46,47]$. More recent studies suggest that cyclic GMP could mediate the effects of low concentrations of nitric oxide in augmenting glucose-induced $\mathrm{Ca}^{2+}$ oscillations and insulin secretion in rat-isolated beta cells [48, 49, 50]. 8-bromoguanosine-cyclic GMP was found to augment glucose-induced $\mathrm{Ca}^{2+}$ oscillations in mouse islets and to inhibit $\mathrm{K}_{\text {ATP }}$ channel activity in mouse-intact beta cells [51]. Cyclic GMP was reported to mediate nitric oxide-induced apoptosis in the insulin-secreting cell line HIT-T15 [52].

\section{PDE isoforms present in the islets}

Relatively little is known about the PDE isoenzymes in the pancreatic islet beta cell. Most studies have used pancreatic islets, which contain four endocrine cell types; these comprise the insulin-secreting beta cells, the glucagon-secreting A cells, the somatostatin secreting D cells and the pancreatic polypeptide cells. Blood vessels also permeate the islets. Thus the presence of a particular PDE in islets does not necessarily indicate its presence in the insulin-secreting cells. This technical problem has been circumvented by the use of insulin-secreting cell lines, although these have limitations as models for native beta cells.

\section{PDE1}

There are three distinct isoforms of the calcium-calmodulin activated PDE1, termed PDE1A, B and C. These isoforms are encoded by distinct genes and show differential tissue expression. Earlier work showed islets to contain a cytosolic Ca-calmodulin activated PDE, with low and high $\mathrm{K}_{\mathrm{m}}$ components for both cAMP and cGMP and a particulate form, which appeared insensitive to Ca-calmodulin [53, 54, 55]. We have recently shown a calcium-calmodulin activated PDE activity in the pellet, but not the supernatant, fraction of homogenates of an insulin-secreting cell line BRIN BD11 [56].

The presence of a Ca-calmodulin activated PDE was also observed in another beta-cell line $\beta$-TC 3 and furthermore RT-PCR was used to show that this isoform was PDE1C [4]. Thus islets, and possibly beta cells, express PDE1. This is supported to some extent by the observation that the PDE1/PDE5 inhibitor zaprinast $\left(10^{-5}-10^{-4} \mathrm{~mol} / \mathrm{l}\right)$ produced a 14 to $30 \%$ inhibi- 
tion in both membrane and cytosolic fractions of rat islet homogenates [57] and 25\% inhibition of cyclic AMP/cyclic GMP PDE activity in BRIN-BD11 cells ( $\mathrm{IC}_{50} \sim 1-5 \mu \mathrm{mol} / 1$, [56]. A study [4] also showed that the PDE was inhibited by zaprinast $\left(\mathrm{IC}_{50} 4.5 \mu \mathrm{mol} / \mathrm{l}\right)$ or 8-MM-IBMX ( $\left.\mathrm{IC}_{50} 7.5 \mu \mathrm{mol} / \mathrm{l}\right)$ but not by vinpocetine $\left(\mathrm{IC}_{50}>100 \mu \mathrm{mol} / \mathrm{l}\right.$ for PDE1C vs $1.4 \mu \mathrm{mol} / 1$ and $9.8 \mu \mathrm{mol} / 1$ for PDE1A and PDE1B) $[5,6]$; these findings were compatible with the presence of PDE1C but not PDE1A or PDE1B. Although the data support the presence of a PDE1, other isoforms are clearly expressed, as evidenced by the presence in islets [57] or beta-cell lines $[4,56]$ of zaprinast-insensitive PDE activity.

\section{PDE3}

Islet PDE activity was inhibited by 60 to $70 \%$ using $10 \mu \mathrm{mol} / 1$ cyclic GMP [58]. The pellet fraction of homogenates of BRIN BD11 cells was also found to contain a cyclic AMP PDE activity that was potently $\left(\mathrm{IC}_{50}-0.7 \mu \mathrm{mol} / \mathrm{l}\right)$ inhibited (up to $30-40 \%$ ) by cyclic GMP [56]. Moreover, the membrane and cytosolic fractions of islet homogenates contained a low $\mathrm{K}_{\mathrm{m}}$ (1.4-2.2 $\mu \mathrm{mol} / \mathrm{l})$ cyclic AMP PDE activity [57]. These data are consistent with the presence of PDE3 in insulin-secreting cells. There are two isoforms of PDE3 (PDE3A and PDE3B) and there is convincing evidence that only PDE3B is expressed in the beta cell. For example, the use of a polyclonal antibody against a GST-PD3B, showed a single protein band in western blots of extracts of rat pancreatic islets and the betacell line HIT-T15 that corresponded in size to the PDE3B protein found in extracts of rat epididymal adipose tissue [59]. Furthermore, we applied RT-PCR to total RNA of BRIN-BD11 cells and amplified a product using PDE3B-specific primers. The product showed over 97\% sequence homology with rat adipose tissue PDE3B [56]. No product was obtained using PDE3A-specific primers. The presence of PDE3B in native beta cells was also supported strongly by immunocytochemistry, showing that in rat islets PDE3B was expressed only in cells that were co-stained with anti-insulin antibodies [59].

Pharmacological characterization of PDE3 has been greatly facilitated by the development of potent, highly selective inhibitors of this isoform, such as SK\&F 94836 (siguazodan) [60] and Org 9935 [61]. We found that SK\&F 94836 and Org 9935 were very potent inhibitors of rat islet PDE activity, especially in membrane fractions [57] with up to $85 \%$ of membrane-bound PDE being inhibited with $\mathrm{IC}_{50}$ values of 5.5 and $0.05 \mu \mathrm{mol} / 1$ respectively. Of interest, we have also made similar observations in human islets [62]. This was later confirmed by others [63], who showed that rat and human islets contained a milrinone-sensitive PDE, accounting for up to $70 \%$ of total islet PDE activity. In addition, the PDE activity in anti-PDE3Bimmunoprecipitates was completely inhibited by milrinone [59]. Again, recent work showed SK\&F 94836 and Org 9935 to inhibit cyclic AMP PDE in the BRIN BD11 insulin-secreting cell line [56]. Unlike in islets, we found that these drugs inhibited cyclic AMP hydrolysis only in the membrane fraction of BRINBD11 cell homogenates. We proposed that the PDE3 activity found in the soluble fraction of homogenates of rat islets might be PDE3A from blood vessels or other non-beta-cell tissue. PDE3A was shown exclusively in the cytosolic fractions of all tissues studied, whereas PDE3B was expressed in particulate fractions [64].

\section{PDE4}

Some experiments showed rolipram to be without effect on cyclic AMP hydrolysis in rat islet homogenates. However, in other experiments homogenate cyclic AMP-PDE activity was inhibited up to $20 \%$ by rolipram in concentrations of $10^{-5}$ to $10^{-4} \mathrm{~mol} / \mathrm{l}$ [57], although this inhibitory effect is labile. These findings have been confirmed [63], while another study [4] reported a rolipram sensitive cyclic AMP PDE activity in $\beta$ TC3 cells and showed the expression of PDE4A and PDE4D using RT-PCR. We reported that approximately $25 \%$ of the BRIN-BD11 cell homogenate cyclic AMP PDE activity in both cytosolic and membrane fractions were inhibited by rolipram $\left(\mathrm{IC}_{50}\right.$ 0.04-0.1 $\mu \mathrm{mol} / \mathrm{l})$ [56]. Taken together, these results suggest that beta cells express functional PDE4.

\section{Other PDE isoforms}

A combination of maximal inhibitory concentrations of Org 9935 (PDE3), rolipram (PDE4) and zaprinast (PDE1/5) inhibited BRIN-BD11 cell cyclic AMP PDE at low substrate concentrations by around 90\%. A similar degree of inhibition was obtained by maximal inhibitory concentrations of the non-selective PDE inhibitor IBMX. Thus the total cyclic AMP PDE activity could be largely accounted for by PDE1, PDE3 and PDE4. The $\sim 10 \%$ activity not inhibited by IBMX could be attributable to the IBMX-insensitive, cyclic AMP specific enzyme PDE8, although there is no other direct evidence for this. We have also found that Western blotting of islet homogenates showed a protein band corresponding to PDE10A. The significance of this finding has yet to be determined. However, the very low Km for cyclic AMP of PDE10 suggests that these isoforms could function to control basal cyclic AMP under conditions of glucose fasting or in the absence of circulating GLP-1. 


\section{Role of islet beta-cell PDE in modulating insulin secretion}

Modulation of glucose-induced insulin secretion by PDE inhibitors

The non-selective PDE inhibitor IBMX has been shown by many authors to augment glucose-induced insulin secretion and has been used widely as a tool to investigate the role of cyclic AMP in the beta cell. However, apart from its lack of selectivity for different PDE isoforms, IBMX could have actions that are not related to PDE-inhibitory activity, for example activation of the ryanodine receptor [65] and antagonism at adenosine receptors [66]. We found that several selective PDE3 inhibitors (Org 9935, siguazodan, SK\&F 94120, ICI118233) augmented glucose-induced insulin secretion from rat and human islets, whereas selective inhibitors of PDE4 and PDE1/5 did not $[57,62]$. Other selective PDE3 inhibitors were also found to augment insulin secretion. Thus, milrinone augmented glucose-induced insulin secretion in rat [4] and human [63] isolated islets and pimobendan augmented glucose-induced insulin secretion in rat islets [67]. Milrinone also augmented glucose-induced insulin secretion by monolayers of neonatal rat pancreatic monolayer cells [59], excluding an indirect effect by modulating the secretion of other islet hormones. Moreover, Org 9935 and siguazodan augmented glucose-induced insulin secretion in the insulin-secreting cell line BRIN-BD11 [56] and OPC3911 produced a similar effect in INS-1(832/13) cells [23]. These data strongly support a role for PDE3, rather than other isoforms, in regulating the cyclic AMP pool that modulates insulin secretion. However, this is complicated by the observations that glucose-induced insulin secretion is augmented in beta-cell lines, as distinct from intact islets, by rolipram, a selective PDE4 inhibitor $[4,56]$. There is good evidence in other, non-beta-cell systems for compartmentalization of PDEs [68, 69, 70]. Therefore compartmentalization of PDE4 isoforms might be different between beta-cell lines and native beta cells. In cell lines, PDE4 can interact with relevant cyclic AMP pools regulating insulin secretion due to its relocalisation into compartments containing the insulin secreting machinery. A further and more intriguing complication arises from the observation that 8-MMIBMX, purported to be a selective inhibitor of the Cacalmodulin activated PDE1C isoform, augmented glucose-induced insulin secretion in both $\beta$-TC 3 cells and in islets [4]. Zaprinast, a PDE1/5 inhibitor also augmented glucose-induced insulin secretion in $\beta$ TC3 cells. The selectivity of 8-MM-IBMX for PDE1C at the concentrations (150 and $500 \mu \mathrm{mol} / \mathrm{l})$ used to modulate insulin secretion is not clear. Moreover, the reason for the discrepancy between these observations and those in which zaprinast either had no effect $[56,57]$ or, in some conditions, inhibited [57] glucose-induced insulin secretion is not known.

Mechanisms underlying the augmentation of glucoseinduced insulin secretion by PDE3 inhibitors. Caution must be exercised in interpreting the effects of all "selective" PDE inhibitors because it has not been established that their effects on insulin secretion are mediated solely through inhibition of cyclic AMP hydrolysis. For example, effects of the selective PDE3 inhibitor pimobendan could involve a calcium-sensitising effect unrelated to PDE inhibition [67]. Effects of selective PDE3 inhibitors on glucose-induced insulin secretion can be shown in the absence of a measured increase in cyclic AMP concentrations [57,67] although the agents clearly increased cyclic AMP when adenylyl cyclase was activated by forskolin [57]. In $\beta$ TC3 cells rolipram (PDE4) and 8-MM-IBMX (PDE1C) but not milrinone (PDE3) produced modest increases in cyclic AMP [4]. The failure consistently to demonstrate global increases in islet cyclic AMP concentrations in response to the selective PDE3 inhibitors could reflect compartmentalization of the PDEs as has been shown in a number of other systems, including adipocytes and cardiovascular tissues [70, 71, 72]. Moreover, cyclic AMP accumulated as a result of selective inhibition of PDE3 can be destroyed by other PDE isoforms as it diffuses from its site of action. Although detailed studies on the compartmentalization of PDE3B in the islet beta cell have not been carried out, it is clear that the enzyme is membrane bound [23, 56, 57]. Nevertheless, effects of PDE3 inhibitors in the islets are compatible with effects mediated through cyclic AMP. Thus, the selective PDE3 inhibitor Org 9935 increased $\left[\mathrm{Ca}^{2+}\right]_{\mathrm{i}}$ in rat intact, isolated islets of Langerhans [73]. The selective PDE3 inhibitor OPC3911 augmented $\mathrm{Ca}^{2+}$-induced exocytosis from INS-1(832/13) cells in the presence of normal intracellular concentrations of cyclic AMP but not when cyclic AMP was replaced by the PDE-resistant cyclic AMP analogue Sp-cAMPS [23]. OPC3911 also augmented depolarization-evoked exocytosis when a submaximal concentration of forskolin $(500 \mathrm{nmol} / \mathrm{l})$ was present to increase basal cyclic AMP concentrations [23].

Effect of over-expression of PDE3B. Strong evidence supporting a role for PDE3B in the beta cell has been obtained using alternative approaches (thereby validating studies based on pharmacological inhibition) in which adenoviral plasmid constructs were used to over-express PDE3B in insulinoma cells and native rat islets [23]. This resulted in a six- to eightfold over-expression in membrane-associated PDE3B activity. Insulin secretion in response to glucose and GLP-1-mediated augmentation of glucose-induced insulin secretion were markedly reduced, consistent with an opposing action of PDE3B on insulin release. Moreover, cy- 


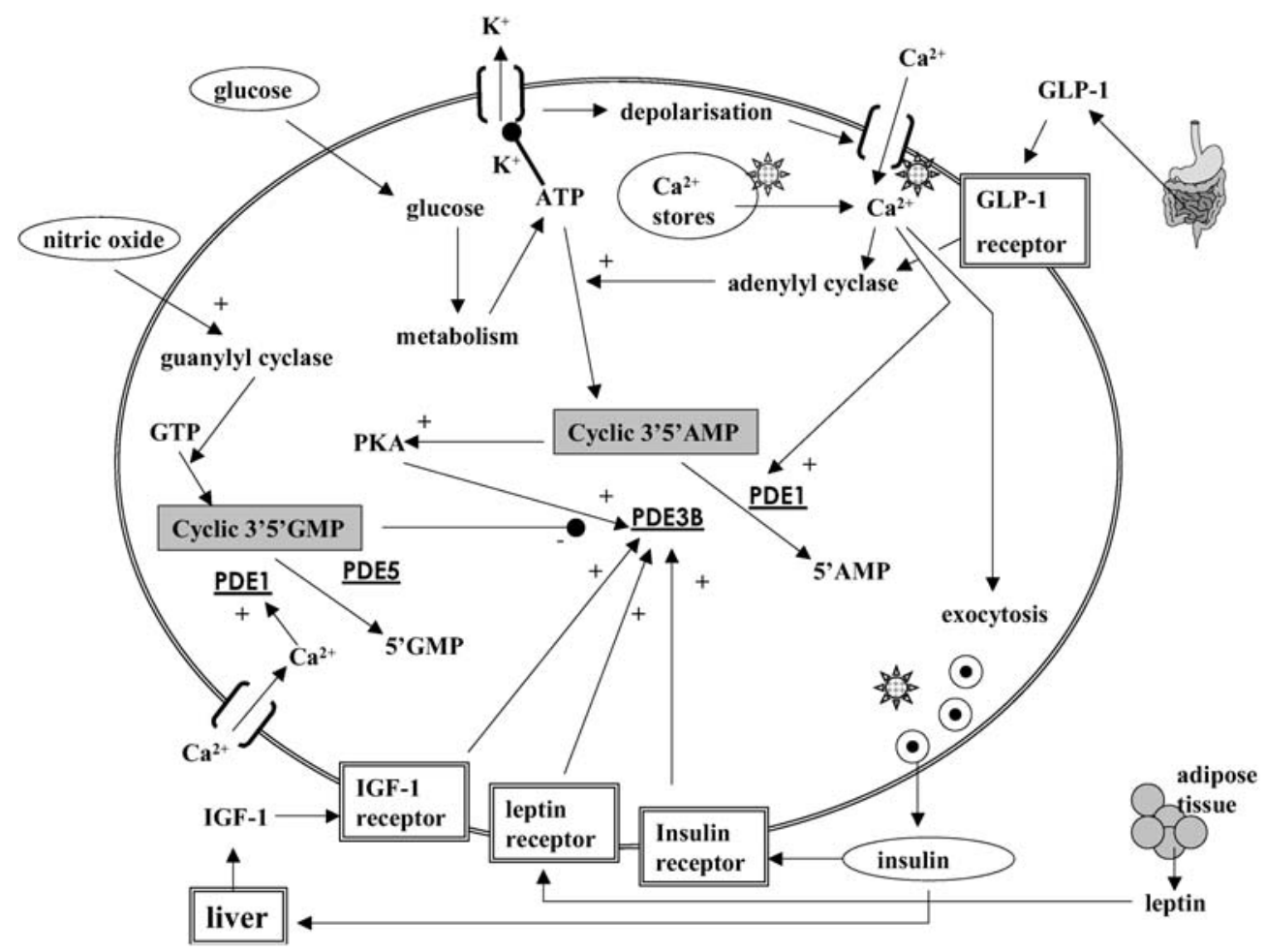

Fig. 1. Hypothetical regulation of pancreatic islet beta-cell phosphodiesterases. Some sites of action ofcAMP in amplifying glucose-induced insulin secretion are indicated by the star symbol (see also the text)

clic AMP augmentation of $\mathrm{Ca}^{2+}$-induced exocytosis measured by capacitance changes in patch-clamped in single beta cells was also considerably diminished in cells over-expressing PDE3B, whereas the response to a PDE-resistant cAMP analogue (Sp-CAMPS) was not modified.

The involvement of PDE3 in regulating the cyclic AMP pool relevant to insulin secretion could, in part, explain the conflicting findings concerning the role of cyclic GMP in beta-cell function. Increases in cyclic GMP could inhibit beta-cell PDE3, leading to increases in cyclic AMP. Thus any direct effects of cyclic GMP could be confounded indirectly by the actions of cyclic AMP. This cross-talk has not yet been found in the islet beta cell but does occur in other cell types, including endocrine cells. For example, the increase in renin secretion from renal juxtaglomerular cells in response to nitric oxide could be mediated by a rise in cyclic AMP as a result of cyclic GMP-mediated inhibition of PDE3 [74]. This could explain the increased glucose-induced insulin release in response to the PDE1/5 inhibitor zaprinast reported by [4], although we found no such effect either in islets or in a betacell line [56].
Regulation of PDEs in the pancreatic islet beta cell

Relatively little is known about the long- or short-term regulation of PDEs in the islet beta cell. In other tissues PDE1, by definition, is activated by calcium-calmodulin and, as described above, there is evidence for this in the pancreatic islet beta cell, although the role of this regulation in modulating insulin secretion or other islet beta cell functions has not been established. In a thyroid cell line, PDE4 is rapidly activated by cyclic AMP through a PKA-mediated phosphorylation [75], whereas in smooth muscle both PDE3 and PDE4 are activated in a similar fashion [76]. The role of PKA-catalysed activation of these enzymes has not yet been investigated in the pancreatic islet beta cell. The PDE3 activity of the pancreatic islet beta cell seems to be regulated by insulin, insulin-like growth factor-1 (IGF-1), leptin and by glucose itself. The regulation of PDEs in the pancreatic islet beta cell is summarized in Fig. 1 and is further described below.

Insulin and insulin-like growth factor-1 (IGF-1). It is well known that insulin activates PDE3B in adipocytes and that this contributes importantly to the antilipolytic effects of insulin [71]. Insulin receptors have been observed on the beta cell [77] and insulin was shown in some studies to inhibit its own release [77, $78,79]$. Thus this inhibition could be achieved by insulin-mediated activation of beta-cell PDE3 and consequent reduction in beta-cell cyclic AMP concentrations. However, we were unable to show any effect of insulin on PDE activity in freshly isolated rat islets [57]. In contrast IGF-1 potently activated PDE activity in neonatal rat pancreatic monolayer cell cultures [59] 
and in BRIN-BD11 cells $[43,56]$, through a PI-3 kinase-dependent pathway [43]. Another study [59] also showed that IGF-1 reduced cyclic AMP concentrations. Moreover, IGF-1 attenuated the augmentation of glucose-induced insulin release produced by the PDE3B-hydrolyzable cyclic AMP analogue 8-Br- cyclic AMP but not that produced by the non-hydrolyzable $N^{6}$-benzoyl-cAMP, further suggesting that its effects were due to activation of PDE. Moreover, these effects of IGF-1 were prevented by inhibition of PDE3 using milrinone. Thus insulin at high concentrations acting through low-affinity binding to IGF-1 receptors, or at physiological concentrations through insulin receptors, might modulate its own release via PDE3B activation. The finding that inhibitors of PI-3 kinase augmented insulin secretion is compatible with this hypothesis [80].

Leptin. Leptin markedly inhibited GLP-1-augmentation of glucose-induced insulin release in a neonatal rat pancreatic culture [81]. This effect was accompanied by a reduction in cyclic AMP concentrations and an activation of PDE. Activation of PDE3B probably occurs via a cytokine-dependent regulation of IRS-1/2 and associated binding of PI3K. Indeed, PKB is a possible candidate for phosphorylation of PDE3B in response to both leptin and IGF-1. Leptin attenuated the augmentation of glucose-induced insulin release produced by the PDE3B-hydrolyzable cyclic AMP analogue 8-Br-cAMP but not that produced by the nonhydrolyzable $N^{6}$-benzoyl-cAMP, further suggesting that its effects were due to activation of PDE [81]. However, the role of PDE activation in leptin-induced inhibition of insulin secretion in vivo was questioned in view of the failure of the PDE3 inhibitor milrinone to abrogate this inhibition [82].

Glucose. PDE1 activity was increased in the insulin-secreting cell line $\beta$ TC 3 when the cells were cultured in a high glucose medium and was reduced in glucose-deprived cells [4]. On the other hand, a short-term increase of glucose concentrations (to $11.1 \mathrm{mmol} / \mathrm{l}$ ) activated PDE3B activity in another insulin secreting cell line (HIT-T15) [58]. The mechanisms underlying the effects of glucose in these cell lines has not been investigated.

\section{PDEs in other islet cell types}

There are no studies concerning the PDE enzymes present in the other cell types of the islets. However, protein kinase A mediates the effect of adrenaline on glucagon secretion [83] and glucagon synthesis and secretion are stimulated by a combination of forskolin and IBMX $[84,85]$. Thus, the presence of the adenylyl cyclase-cyclic AMP-PKA system strongly indicates that phosphodiesterases are likely to be present and functionally active in the islet A-cell. It is important to determine their nature and how they modulate glucagon secretion.

\section{Is there potential for the therapeutic application of PDE inhibitors in treating diabetes mellitus?}

Type 2 diabetes mellitus is characterised by impaired insulin secretion and peripheral insensitivity to the hormone [86]. Treatment of Type 2 diabetes is currently unsatisfactory and new agents are needed. One approach is to develop non-sulphonylurea drugs that will augment insulin secretion through mechanisms other than blocking $\mathrm{K}_{\text {ATP }}$ channels. Agents increasing islet beta-cell cyclic AMP have potential as therapeutic agents and GLP-1 and its derivatives have been shown to normalise insulin responses to glucose and almost to normalize overnight and daytime glucose concentrations $[87,88]$. However, GLP-1 has the disadvantages associated with peptides, namely rapid degradation and inactivity by the oral route. Selective inhibition of PDE3 in the islet beta cell will augment meal-related insulin secretion, because of the amplification of the effect of incretin factors, particularly GLP-1. Thus PDE3 offers a target for developing drugs for the treatment of Type 2 diabetes mellitus. Development of PDE3 inhibitors for this purpose will require their selectivity for islet beta cell PDE3, as PDE3 seems also to be the important isoenzyme in the liver and adipose tissue [89], where its activation mediates some of the effects of insulin. Indeed, our in vivo work showed that a potent PDE3 inhibitor, Org 9935, considerably augmented glucose-induced increases in plasma insulin concentrations, but did not modify plasma glucose concentrations, possibly due to concomitant inhibition of hepatic and adipose tissue PDE3 [90]. Milrinone improved glucose tolerance in the normal mouse but was hyperglycaemic in the $o b / o b$ mouse, despite increases in plasma insulin [91]. This group also showed milrinone to antagonise insulin-mediated inhibition of lipolysis in isolated adipocytes and insulin-mediated inhibition of glucose production in isolated hepatocytes. Of interest, the non-selective PDE inhibitor caffeine was shown recently to augment glucose-induced increases in serum insulin concentrations, while tending to increase blood glucose during OGTT in young, healthy male volunteers, again suggesting insulin resistance [92]. These observations could explain why metabolic effects such as hypoglycaemia were not reported in the major clinical trial of the PDE3 inhibitors milrinone for heart failure [93]. Although highly speculative, hyperinsulinaemia might have contributed to the higher mortality in milrinone-treated patients in this trial, as hyperinsulinaemia could activate PAI-1 [94], thereby impairing fibrinolysis.

Another intriguing possibility lies in the potential of PDE inhibitors to prevent beta-cell loss in both Type 1 and Type 2 diabetes. The non-selective PDE 
inhibitor pentoxifylline and the PDE4-selective agent rolipram were shown to reduce insulitis and prevent diabetes in non-obese diabetic (NOD) mice [95]. While this effect can be explained by inhibition of cytokine production by pro-inflammatory cells such as macrophages there could also be a contribution from an inhibition of nitric oxide production by islet cells in response to cytokines. Thus pentoxifylline and the selective PDE3 inhibitor cilostamide blocked nitric oxide production by mouse islet cells and a beta-cell line (NIT-1) in response to stimulation by lipopolysaccharide and inflammatory cytokines [96] and prevented the expression of inducible nitric oxide synthase both in vitro and in vivo in the NOD mouse. This supports earlier findings that IBMX reduced IL- $1 \beta$ induced nitric oxide synthase expression and nitric oxide production in rat islets, an effect mimicked by dibutyryl cyclic AMP [41]. However, much more work is needed to clarify the role of cyclic AMP in preventing beta-cell death, especially in view of the promotion of apoptosis by exposure to dibutyryl cyclic AMP [42] or forskolin [43] in beta-cell lines. Indeed, we have reported that serum withdrawal-induced apoptosis of BRIN BD11 cells is associated with impaired IGF-1dependent regulation of PDE3B [43], which is predicted to induce increases in intracellular cyclic AMP perhaps leading to dysfunctional regulation of $\mathrm{BAD} / \mathrm{Bcl} 2$ and thereby promoting apoptosis.

\section{Summary and conclusions}

Many questions about islet PDEs remain to be answered, including their regulation and distribution and sub-cellular compartmentalization within the pancreatic islet beta cell, the nature of the important enzyme isoforms in the glucagon and somatostatin-secreting cells, the role of PDEs in turning off or moderating physiological, meal-related glucose-induced insulin secretion and the possibility of selective inhibition of beta cell PDE3B with a view to its exploitation in the treatment of Type 2 diabetes. In the last context, although PDE3A and PDE3B are sufficiently different to allow the development of inhibitors selective for either isoform, there is no evidence that PDE3B in the islets can be inhibited selectively, relative to PDE3B in adipocytes or hepatocytes. However, a novel piperazine hypoglycaemic agent has been described [97] which augmented insulin secretion, and which was shown to inhibit PDE in islets and was a competitive inhibitor of recombinant PDE3 and PDE4, being fourto fivefold more potent in inhibiting PDE4. This serendipitous observation could indicate that there are some subtle differences between the PDE3B in islets and the other tissues, which allow selective inhibition. In contrast, the development of PDE3A selective agents could allow the treatment of cardiovascular disease without producing metabolic adverse effects such as hyperinsulinaemia and insulin resistance. Target validation is essential before pursuing development of therapeutic agents designed to inhibit PDE3B for the treatment of patients with Type 2 diabetes. Future studies should therefore focus on development of PDE3B knockouts or transgenics to establish whether alteration in PDE3B gene expression can modulate insulin secretion/glucose tolerance in models of Type 2 diabetes. Such knockouts or transgenics will also define complex relationships between the IGF-1- and insulin-mediated regulation of PDE3B in terms of modulating insulin secretion in vivo. They will also enable assessment of redundancy in the cAMP-PKA-PDE signalling axis in beta cells, for example, by determining if PDE4 can sub-serve the function of PDE3 in PDE3B knockouts. Finally, it is very important to establish how PDE3B expression can be regulated in the islet beta cell. This will be facilitated by identifying key regulatory elements in the PDE3B gene promoter. For instance we have recently shown that the transcription factors CREB and NFkB can regulate expression of PDE3A and PDE5 respectively in pulmonary smooth muscle [98]. It would be of interest to establish whether such regulatory factors influence the expression of PDE3B in islet beta cells. CREB is regulated by PKA-catalysed phosphorylation and its actions could therefore be involved in up-regulation of PDE3 as a means of long-term desensitization of the amplifying effects of cAMP on glucose-mediated insulin secretion. Whether PDE3B inhibitors induce long-term up-regulation of PDE3B expression to ultimately blunt the effects of these inhibitors on insulin secretion has not been defined. NFkB is activated by acute inflammatory reactions and could play a role in inducing up-regulation of PDE3 as a means of protecting against cytokine-induced apoptosis of islet beta cells. In this context, PDE3B might play an important role in reducing apoptosis of islet beta cells in Type 1 diabetes, but clearly the advantages of its up-regulation could be counterbalanced by deleterious effects on the amplifying effects of cAMP on glucose-induced insulin secretion.

Sources. The review is based on the relevant literature published in the English language during the period 1980-2003. The sources available to the authors were integrated through PubMed searches for "PDE and insulin secretion", "PDE and beta-cell function", "cAMP and insulin secretion" and "cAMP and beta cell function". In all animal work undertaken by the authors was performed under the Animals (Scientific Procedures) Act 1986 and conformed to the 'Principles of laboratory animal care' (NIH publication no. 85-23, revised 1985; http://grants1.nih.cgov/ grants/onlaw/references/phspol.htm).

Acknowledgements. We are grateful to P. Owen for editorial assistance. 


\section{References}

1. Perry MJ, Higgs GA (1998) Chemotherapeutic potential of phosphodiesterase inhibitors. Curr Opin Chem Biol 2:472481

2. Mehats C, Andersen CB, Filopanti M (2002) Cyclic nucleotide phosphodiesterases and their role in endocrine cell signaling. Trends. Endocrinol Metab 13:29-35

3. Soderling SH, Beavo JA (2000) Regulation of cAMP and cGMP signaling: new phosphodiesterases and new functions. Curr Opin Cell Biol 12:174-179

4. Han P, Werber J, Surana M et al. (1999) The calcium/calmodulin-dependent phosphodiesterase PDE1C down-regulates glucose-induced insulin secretion. J Biol Chem 274: 22337-22344

5. Clapham JC, Widerspin AF (2001) Cloning of dog heart PDE1A - a first detailed characterization at the molecular level. Gene 268:165-171

6. Yan C, Zhao AZ, Bentley JK et al. (1995) Molecular cloning and characterization of a calmodulin-dependent phosphodiesterase enriched in olfactory sensory neurons. Proc Nat Acad Sci USA 92:9677-9681

7. Pyne NJ, Cooper ME, Houslay MD (1986) Identification and characterization of both the cytosolic and particulate forms of cyclic GMP-stimulated cyclic AMP phosphodiesterase from rat liver. Biochem J 234:325-334

8. Pyne NJ, Cooper ME, Houslay MD (1987) The insulinand glucagon-stimulated 'dense-vesicle' high-affinity cyclic AMP phosphodiesterase from rat liver. Purification, characterization and inhibitor sensitivity. Biochem J 242: 33-42

9. Harrison SA, Reifsnyder DH, Gallis B et al. (1986) Isolation and characterization of bovine cardiac muscle cGMPinhibited phosphodiesterase: a receptor for new cardiotonic drugs. Mol Pharmacol 29:506-514

10. Torphy TJ (1998) Phosphodiesterase isozymes. Molecular targets for novel antiasthma agents. Am J Respir Crit Care Med 157:351-370

11. Houslay MD (1998) Adaptation in cyclic AMP signalling processes: a central role for cyclic AMP phosphodiesterases. Semin Cell Dev Biol 9:161-167

12. Corbin JD, Francis SH (1999) Cyclic GMP phosphodiesterase-5: target of sildenafil. J Biol Chem 274:1372913732

13. Pittler SJ, Baehr W, Wasmuth JJ et al. (1990) Molecular characterization of human and bovine rod photoreceptor cGMP phosphodiesterase alpha-subunit and chromosomal localization of the human gene. Genomics 6:272-283

14. Michaeli T, Bloom TJ, Martins T et al. (1993) Isolation and characterization of a previously undetected human cAMP phosphodiesterase by complementation of cAMP phosphodiesterase- deficient Saccharomyces cerevisiae. J Biol Chem 268:12925-12932

15. Fisher DA, Smith JF, Pillar JS et al. (1998) Isolation and characterization of PDE9A, a novel human cGMP-specific phosphodiesterase. J Biol Chem 273:15559-15564

16. Fujishigi K, Kotera J, Michibata H et al. (1999) Cloning and characterization of a novel human phosphodiesterase that hydrolyzes both cAMP and cGMP (PDE10A). J Biol Chem 274:18438-18445

17. Fawcett L, Baxendale R, Stacey P et al. (2000) Molecular cloning and characterization of a distinct human phosphodiesterase gene family: PDE11A. Proc Natl Acad Sci USA 97:3702-3707

18. Lester LB, Langenberg LK, Scott JD (1997) Anchoring of protein kinase A facilitates hormone-mediated insulin secretion. Proc Natl Acad Sci USA 94:14942-14947
19. Persaud SJ, Jones PM, Howell (1990) Glucose-stimulated insulin secretion is not dependent on activation of protein kinase A. Biochem Biophys Res Commun 173:833-839

20. Grill V, Cerasi E (1973) Activation by glucose of adenyl cyclase in pancreatic islets of the rat. FEBS Lett 33: 311-314

21. Sharp GW (1979) The adenylate cyclase-cyclic AMP system in islets of Langerhans and its role in the control of insulin release. Diabetologia 16:287-296

22. Holz GG, Habener JF (1992) Signal transduction crosstalk in the endocrine system:pancreatic beta-cells and the glucose competence concept. Trends Biochem Sci 17 388-393

23. Harndähl L, Jing XJ, Ivarsson R et al. (2002) Important role of phosphodiesterase $3 \mathrm{~B}$ for the stimulatory action of cAMP on pancreatic beta-cell exocytosis and release of insulin. J Biol Chem 277:37446-37455

24. Kanno T, Suga S, Wu J et al. (1998) Intracellular cAMP potentiates voltage-dependent activation of L-type $\mathrm{Ca}^{2+}$ channels in rat islet beta-cells. Pflugers Arch 435:578-580

25. Kang G, Chepurny OG, Holz GG (2001) cAMP-regulated guanine nucleotide exchange factor II (Epac2) mediates $\mathrm{Ca}^{2+}$-induced $\mathrm{Ca}^{2+}$ release in INS-1 pancreatic beta-cells. J Physiol 536:375-385

26. Islam Md S, Leibiger I, Leibiger B et al. (1998) In situ activation of the type 2 ryanodine receptor in pancreatic beta cells requires cAMP-dependent phosphorylation. Proc Natl Acad Sci USA 95:6145-6150

27. Holz GG, Leech CA, Heller RS et al. (1999) cAMP-dependent mobilization of intracellular $\mathrm{Ca}^{2+}$ by activation of ryanodine receptors in pancreatic $\beta$-cells. A $\mathrm{Ca}^{2+}$ signaling system stimulated by the insulinotropic hormone glucagonlike peptide-(7-37). J Biol Chem 274:14147-14156

28. Yaney GC, Civelek VN, Richard AM et al. (2001) Glucagon-like peptide 1 stimulates lipolysis in clonal pancreatic beta-cells (HIT). Diabetes 50:56-62

29. Renstrom E, Eliasson L, Rorsman P (1997) Protein kinase A-dependent and independent stimulation of exocytosis by cAMP in mouse pancreatic B-cells. J Physiol 502:105-118

30. Kashima Y, Miki T, Shibasaki T et al. (2001) Critical role of cAMP-GEFII-Rim2 complex in incretin-potentiated insulin secretion. J Biol Chem 276:46046-46053

31. Drucker DJ, Philippe J, Mojsov S et al. (1987) Glucagonlike peptide I stimulates insulin gene expression and increases cyclic AMP levels in a rat islet cell line. Proc Natl Acad Sci USA 84:3434-3438

32. Elrick LJ, Docherty K (2001) Phosphorylation-dependent nucleocytoplasmic shuttling of pancreatic duodenal homeobox-1. Diabetes 500:2244-2252

33. Wang X, Zhou J, Doyale ME et al. (2001) Glucagon-like peptide-1 causes pancreatic duodenal homeobox-1 protein translocation from the cytoplasm to the nucleus of pancreatic beta-cells by a cyclic adenosine monophosphate/protein kinase A-dependent mechanism. Endocrinology 142: 1820-1827

34. Ding WQ, Dong M, Ninova D et al. (2003) Forskolin suppresses insulin gene transcription in islet beta-cells through a protein kinase A-independent pathway. Cell Signal $15: 27-35$

35. Jonas JC, Laybutt DR, Steil GM et al. (2001) High glucose stimulates early response gene c-Myc expression in rat pancreatic beta cells. J Biol Chem 276:35375-35381

36. Susimi S, Roche E, Prentki M et al. (1998) Glucose and glucoincretin peptides synergize to induce c-fos, c-jun, junB, zif-268, and nur-77 gene expression in pancreatic beta(INS-1) cells. FASEB J 12:1173-1182

37. Calleja V, Ruiz Enriquez P, Filloux C et al. (1997) The effect of cyclic adenosine monophosphate on the mitogen-ac- 
tivated protein kinase pathway depends on both the cell type and the type of tyrosine kinase-receptor. Endocrinology $138: 1111-1120$

38. Benes C, Roisin MP, Van Tan H et al. (1998) Rapid activation and nuclear translocation of mitogen-activated protein kinases in response to physiological concentration of glucose in the MIN6 pancreatic beta cell line. J Biol Chem 273:15507-15513

39. Benes C, Poitout V, Marie J-C et al. (1999) Mode of regulation of the extracellular signal-regulated kinases in the pancreatic $\beta$-cell line MIN6 and their implication in the regulation of insulin gene transcription. Biochem J 340:219-225

40. Ehses JA, Pelech SL, Pederson RA et al. (2002) Glucosedependent insulinotropic polypeptide activates the RafMek1/2-ERK1/2 module via a cyclic AMP/cAMP-dependent protein kinase/Rap1-mediated pathway. J Biol Chem 277:37088-37097

41. Andersen HU, Mauricio D, Karlsen AE et al. (1996) Interleukin-1 beta-induced nitric oxide production from rat isolated islets is modulated by D-glucose and 3-isobutyl-1methyl xanthine. Eur J Endocrinol 134:251-259

42. Loweth AC, Williams GT, Scarpello JH et al. (1996) Heterotrimeric G-proteins are implicated in the regulation of apoptosis in pancreatic beta-cells. Exp Cell Res 229:69-76

43. Ahmad M, Flatt PR, Furman BL et al. (2000) The role of cyclic GMP-inhibited cyclic AMP-specific phosphodiesterase (PDE3) in regulating clonal BRIN-BD11 insulin secreting cell survival. Cell Signal 12:541-548

44. Vara E, Tamarit-Rodriguez J (1991) Does cyclic guanosine monophosphate mediate noradrenaline-induced inhibition of islet insulin secretion stimulated by glucose and palmitate? Biochem J 278:243-248

45. Green IC, Delaney CA, Cunningham JM et al. (1993) Interleukin-1 beta effects on cyclic GMP and cyclic AMP in culture rat islets of Langerhans-arginine-dependence and relationship to insulin secretion. Diabetologia 36:9-16

46. Verspohl EJ, Ammon HP (1989) Atrial natriuretic peptide (ANP) acts via specific binding sites on cGMP system of rat pancreatic islets without affecting insulin release. Naunyn Schmiedebergs Arch Pharmacol 339:348-353

47. Jones PM, Persaud SJ, Bjaaland T et al. (1992) Nitric oxide is not involved in the initiation of insulin secretion from rat islets of Langerhans. Diabetologia 35:1020-1027

48. Matsuura N, Ishikawa T, Abe S et al. (1999) Nitric oxidecyclic GMP system potentiates glucose-induced rise in cytosolic $\mathrm{Ca}^{2+}$ concentration in rat pancreatic beta-cells. Life Sci 65:1515-1522

49. Smukler SR, Tang L, Wheeler MB et al. (2002) Exogenous nitric oxide and endogenous glucose-stimulated beta-cell nitric oxide augment insulin release. Diabetes 51:34503460

50. Kaneko Y, Ishikawa T, Amano S et al. (2003) Dual effect of nitric oxide on cytosolic $\mathrm{Ca}^{2+}$ concentration and insulin secretion in rat pancreatic (beta)-cells. Am J Physiol Cell Physiol 284:C1215-C1222

51. Ropero AB, Fuentes, E, Rovira JM et al. (1999) Non-genomic actions of $17 \beta$-oestradiol in mouse pancreatic $\beta$ cells are mediated by a cGMP-dependent protein kinase. J Physiol 521:397-407

52. Loweth AC, Williams GT, Scarpello JH (1997) Evidence for the involvement of cGMP and protein kinase $\mathrm{G}$ in nitric oxide-induced apoptosis in the pancreatic B-cell line, HITT15. FEBS Lett 400:285-288

53. Sugden MC, Ashcroft SJH (1981) Cyclic nucleotide phosphodiesterase of rat pancreatic islets. Effects of $\mathrm{Ca}^{2+}$, calmodulin and trifluoperazine. Biochem J 197:459-464
54. Capito K, Hedeskov CJ, Thams P (1986) Cyclic AMP phosphodiesterase activity in mouse pancreatic islets. Effects of calmodulin and phospholipids. Acta Endocrinol 111:533-538

55. Lipson LG, Oldham SB (1983) The role of calmodulin in insulin secretion: the presence of a calmodulin-stimulatable phosphodiesterase in pancreatic islets of normal and pregnant rats. Life Sci 32:775-780

56. Ahmad M, Abdel-Wahab YHA, Tate R et al. (2000) Effect of type-selective inhibitors on cyclic nucleotide phosphodiesterase activity and insulin secretion in the clonal insulin secreting cell line BRIN-BD11. Br J Pharmacol 129:12281234

57 Shafiee-Nick R, Pyne NJ, Furman BL (1995) Effects of type-selective phosphodiesterase inhibitors on glucose-induced insulin secretion and islet phosphodiesterase activity. Br J Pharmacol 115:1486-1492

58. Furman BL, Pyne NJ (1990) Islet phosphodiesterase isoenzymes and insulin secretion. Diabet Med 7:19A

59. Zhao AZ, Zhao H, Teague J et al. (1997). Attenuation of insulin secretion by insulin-like growth factor 1 is mediated through activation of phosphodiesterase 3B. Proc Natl Acad Sci USA 94:3223-3228

60. Thompson WJ (1991) Cyclic nucleotide phosphodiesterases: pharmacology, biochemistry and function. Pharmacol Ther 51:13-33

61. Shahid M, van Amsterdam RG, Boer J de et al. (1991) The presence of five cyclic nucleotide phosphodiesterase isoenzyme activities in bovine tracheal smooth muscle and the functional effect of selective inhibitors. $\mathrm{Br} \mathrm{J}$ Pharmacol 104:471-477

62. Shafiee-Nick R, James RFL, London NJM et al. (1994) Cyclic $3^{\prime} 5^{\prime}$ AMP phosphodiesterases in human islets. Diabet Med 11 (Suppl 1):S31

63. Parker JC, Van Volkenberg MA, Ketchum RJ et al. (1995) Cyclic AMP phosphodiesterases of human and rat islets of Langerhans: contributions of types III and IV to the modulation of insulin secretion. Biochem Biophys Res Commun 217:916-923

64. Liu H, Maurice DH (1998) Expression of cyclic GMP-inhibited phosphodiesterases $3 \mathrm{~A}$ and $3 \mathrm{~B}$ (PDE3A and PDE3B) in rat tissues: differential subcellular localization and regulated expression by cyclic AMP. Br J Pharmacol 125:1501-1510

65. Islam MS (2002) The ryanodine receptor calcium channel of $\beta$-cells: molecular regulation and physiological significance. Diabetes 51:1299-1309

66. Kenakin TP, Beek D (1987) Measuement of antagonist affinity for purine receptors of drugs producing concomitant phosphodiesterase blockade; the use of pharmacological resultant analysis. J Pharmacol Exp Ther 243:482-486

67. Fujimoto S, Ishida H, Kato S et al. (1998) The novel insulinotropic mechanism of pimobendan: direct enhancement of the exocytotic process of insulin secretory granules by increased $\mathrm{Ca}^{2+}$ sensitivity in $\beta$-cells. Endocrinology 139: 1133-1140

68. Jin SL, Bushnik T, Lan L, Conti M (1998) Subcellular localization of rolipram-sensitive, cAMP-specific phosphodiesterases. Differential targeting and activation of the splicing variants derived from the PDE4D gene. J Biol Chem 273:19672-19678

69. Degerman E, Belfrage P, Manganiello VC (1996) cGMPinhibited phosphodiesterases (PDE3 gene family). Biochem Soc Trans 24:1010-1014

70. Shakur Y, Takeda K, Kenan Y et al. (2000) Membrane localization of cyclic nucleotide phosphodiesterase 3 (PDE3). Two N-terminal domains are required for the efficient tar- 
geting to, and association of, PDE3 with endoplasmic reticulum. J Biol Chem 275:38749-38761

71. Degerman E, Belfrage P, Manganiello VC (1997) Structure, localization, and regulation of cGMP-inhibited phosphodiesterase (PDE3). J Biol Chem 272:6823-6826

72. Movsesian MA (2002) PDE3 cyclic nucleotide phosphodiesterases and the compartmentation of cyclic nucleotidemediated signaling in cardiac myocytes. Basic Res Cardiol 97 (Suppl 1):183-190

73. Cruickshank SF, Drummond RM, Furman BL (2002) Inhibition of islet phosphodiesterase PDE3 increases the calcium response to glucose. Br J Pharmacol 135:228P

74. Kurtz A, Gotz KH, Hamann M et al. (1998) Stimulation of renin secretion by nitric oxide is mediated by phosphodiesterase 3. Proc Natl Acad Sci USA 95:4743-4747

75. Sette C, Iona S and Conti M (1994) The short-term activation of a rolipram-sensitive, cAMP-specific phosphodiesterase by thyroid-stimulating hormone in thyroid FRTL-5 cells is mediated by a cAMP-dependent phosphorylation. J Biol Chem 269:9245-9252

76. Murthy KS, Zhou H, Makhlouf GM (2002) PKA-dependent activation of PDE3A and PDE4 and inhibition of adenylyl cyclase V/VI in smooth muscle. Am J Physiol Cell Physiol 282:C508-C517

77. Persaud SJ, Asare-Anane H, Jones PM (2002) Insulin receptor activation inhibits insulin secretion from human islets of Langerhans. FEBS Lett 510:225-228

78. Koranyi L, James DE, Kraegen EW et al. (1992) Feedback inhibition of insulin gene expression by insulin. J Clin Invest 89:432-436

79. Marchetti P, Scharp DW, McLear M (1995) Insulin inhibits its own secretion from isolated, perifused human pancreatic islets. Acta Diabetol 32:75-77

80. Zawalich WS, Tesz GJ, Zawalich KC (2002) Inhibitors of phosphatidylinositol 3-kinase amplify insulin release from islets of lean but not obese mice. J Endocrinol 174:247258

81. Zhao AZ, Bornfeldt KE, Beavo JA (1998) Leptin inhibits insulin secretion by activation of phosphodiesterase 3B. J Clin Invest 102:869-873

82. Cases JA, Gabriely I, Ma XH et al. (2001) Physiological increase in plasma leptin markedly inhibits insulin secretion in vivo. Diabetes 50:348-352

83. Gromada J, Bokvist K, Ding W-G et al. (1997) Adrenaline stimulates glucagon secretion in pancreatic A-cells by increasing the $\mathrm{Ca}^{2+}$ current and the number of granules close to the L-type $\mathrm{Ca}^{2+}$ channels. J Gen Physiol 110:217-228

84. Drucker DJ, Campos R, Reynolds R et al. (1991) The rat glucagon gene is regulated by a protein kinase A-dependent pathway in pancreatic islet cells. Endocrinology 128:394-400
85. Stobie-Hayes KM, Brubacker PL (1996) Inhibition of protein kinase A-induced glucagon synthesis and secretion by glucose. Metabolism 45:347-350

86. Kahn SE (2003) The relative contribution of insulin resistance and beta cell dysfunction to the pathophysiology of Type 2 diabetes. Diabetologia 46:3-19

87. Juhl CB, Hollingdal M, Sturis J et al. (2002) Bedtime administration of NN221, a long-acting GLP-1 derivative, substantially reduces fasting and postprandial glucose in type 2 diabetes. Diabetes 51:424-429

88. Rachman J, Barrow BA, Levy JC et al. (1997) Near-normalisation of diurnal glucose concentrations by continuous administration of glucagon-like peptide-1 (GLP-1) in subjects with NIDDM. Diabetologia 40:205-211

89. Reinhardt RR, Chin E, Zhou J et al. (1995) Distinctive anatomical patterns of gene expression for cGMP-inhibited cyclic nucleotide phosphodiesterases. J Clin Invest 95:15281538

90. El-Metwally M, Shafiee-Nick R, Pyne NJ et al. (1997) The effect of selective phosphodiesterase inhibitors on plasma insulin concentrations and insulin secretion in vitro in the rat. Eur J Pharmacol 324:227-232

91. Parker JC, VanVolkenburg MA, Nardone NA (1997) Modulation of insulin secretion and glycemia by selective inhibition of cyclic AMP phosphodiesterase III. Biochem Biophys Res Commun 236:665-669

92. Graham TE, Sathasivam P, Rowland et al. (2001) Caffeine ingestion elevates plasma insulin response in humans during an oral glucose tolerance test. Can J Physiol Pharmacol 79:559-565

93. Packer M, Carver JR, Rodeheffer RJ et al. (1991) Effect of oral milrinone on mortality in severe chronic heart failure. The PROMISE Study Research Group. N Engl J Med 325:1468-1475

94. Bastard JP, Pieroni L, Hainque B (2000) Relationship between plasma plasminogen activator inhibitor 1 and insulin resistance. Diabetes Metab Res Rev 16:192-201

95. Liang L, Beshay E, Prud'homme GJ (1998) The phosphodiesterase inhibitors pentoxifylline and rolipram prevent diabetes in NOD mice. Diabetes 47:570-575

96. Besay E, Prud'homme GJ (2001) Inhibitors of phosphodiesterase isoforms III or IV suppress islet-cell nitric oxide production. Lab Invest 81:1109-1117

97. Leibowitz MD, Biswas C, Brady EJ et al. (1995). A novel insulin secretagogue is a phosphodiesterase inhibitor. Diabetes 44:66-74

98. Murray F, MacLean MR, Pyne NJ (2002) Increased expression of the cGMP-inhibited cAMP-specific (PDE3) and cGMP binding cGMP-specific (PDE5) phosphodiesterases in models of pulmonary hypertension. Br J Pharmacol 137:1187-1194 